\title{
Small-Dense Low-Density Lipoprotein Cholesterol: A Subclinical Marker for the Primary Prevention of Coronary Heart Disease
}

\author{
Yoshihiro Kokubo, Makoto Watanabe, Aya Higashiyama and Kyoko Honda-Kohmo
}

Department of Preventive Cardiology, National Cerebral and Cardiovascular Center, 6-1, Kishibe-Shinmachi, Suita, Osaka, 5648565 Japan.

Key words: Small-dense LDL cholesterol, Coronary heart disease, Prospective cohort study

\section{See article vol. 27: 669-682}

Many prospective cohort studies have described traditional risk factors for incident coronary heart disease $(\mathrm{CHD})^{1)}$. In 1961, the Framingham Heart Study, the first well-designed large-scale cardiovascular cohort study, identified major risk factors for CHD, including high blood pressure, high cholesterol level, and left ventricular hypertrophy. These factors laid the foundation for later multivariable 10-year ${ }^{2)}$ and 30-year ${ }^{3)}$ risk-prediction algorithms. In recent years, the Japan Atherosclerotic Society has adopted the Suita Score ${ }^{4)}$, which comprehensively evaluates the fundamental risk of CHD and has set lipid target values for lipid management in daily clinical practice based on this risk score $^{5)}$. As the lipid management targets for the primary prevention of $\mathrm{CHD}$, management categories for lipid levels consist of low, moderate, and high risks. The prediction probability of CHD onset within 10 years can be obtained using simple examination items such as medical examination results and general outpatient. The C-statistic for this risk model is 0.83 . It is necessary to search for residual risks that improve this risk model of the predictability of CHD.

In this issue of the Journal of Atherosclerosis and Thrombosis, Higashioka et al. examined the association between small-dense low-density lipoprotein cholesterol (sdLDLC) and the risk of CHD in the Hisayama Study ${ }^{6}$ in which a total of 3,080 subjects (aged 40 years or older) without cardiovascular disease (CVD) at baseline were followed for 8 years. Dr. Higashioka and her colleagues report that, in a Japanese population, the serum sdLDLC level was a relevant biomarker for the future development of $\mathrm{CHD}$ and that it both offers benefits beyond the serum lowdensity lipoprotein cholesterol (LDLC) level and may be a possible therapeutic target for the burden of CHD. Their subjects in the highest quartile of sdLDLC level had a 5.4-fold higher risk of incident CHD than those in the lowest quartile (95\% confidence intervals [CIs], 2.1-13.8). This association remained significant even after additional adjustment of LDLC. When the serum sdLDLC levels were incorporated into a model with established traditional risk factors, the C-statistic, continuous net reclassification improvement, and integrated discrimination improvement were all significantly improved.

From these results, it could be said that sdLDLC is the residual risk as a predictor of incident CHD. A further reproducibility study is necessary due to the small number of CHD cases in this study, although the Hisayama Study is a follow-up study that continues for more than half a century (founded in 1961) with extremely high accuracy control for each survey item and extreme accuracy for an autopsy to determine the cause of death. In addition, that study has used frozen serum samples that had been stored at $80^{\circ} \mathrm{C}$ for more than 10 years, although no significant difference was observed between the blood samples that were collected without freezing and those that were frozen and then thawed ${ }^{7}$.

In a previous cohort study in Japan, the Suita Study, a total of 2,034 general urban Japanese residents were followed for an average of 11 years, and the analyses revealed that, in the men and women, the sdLDLC per $10 \mathrm{mg} / \mathrm{dL}$ had a 1.2- and 1.3-fold higher risk of incident CVD, respectively ${ }^{8)}$. In addition, the subjects in the highest quartile of sdLDLC level had a 3.3-fold higher risk of incident CHD than those in

Address for correspondence: Yoshihiro Kokubo, Department of Preventive Cardiology, National Cerebral and Cardiovascular Center, 6-1, Kishibe-Shinmachi, Suita, Osaka, 564-8565 Japan E-mail: y-kokubo@umin.ac.jp

Received: May 9, 2020 Accepted for publication: May 10, 2020

Copyright@2020 Japan Atherosclerosis Society

This article is distributed under the terms of the latest version of CC BY-NC-SA defined by the Creative Commons Attribution License. 
the lowest quartile (95\% CIs, 1.3-8.2). The cutoff value of the fourth quartile of sdLDLC in the Hisayama Study was $43.7 \mathrm{mg} / \mathrm{dL}$, whereas that in the Suita Study was $49.1 \mathrm{mg} / \mathrm{dL}$ (men, $53.5 \mathrm{mg} / \mathrm{dL}$; women, $44.7 \mathrm{mg} / \mathrm{dL}$ ).

In a cohort study conducted in the U.S., the Multi-Ethnic Study of Atherosclerosis followed 4,387 subjects for an average of 8.5 years, and the authors reported that the subjects in the highest quartile of sdLDLC $(\geq 51.0 \mathrm{mg} / \mathrm{dL})$ had a 2.4 -fold increased risk of incident CHD compared to the lowest sdLDLC levels $(<28.6 \mathrm{mg} / \mathrm{dL})^{9)}$. The association of the highest quartile of sdLDLC with CHD risk remained significant among the subjects with normal LDLC levels ( $<$ $100 \mathrm{mg} / \mathrm{dL}$ ) (hazard ratio, 2.37; 95\% CIs, 1.21-4.67). In addition, the Atherosclerosis Risk in Communities Study followed 10,225 subjects for an average of 11 years and demonstrated that the subjects with elevated plasma sdLDLC levels (the highest quartile) had a 1.5-fold increased risk of incident CHD in a multivariable model compared to the lowest quartile of sdLDLC $^{10)}$. Among the subjects with LDLC $<100$ $\mathrm{mg} / \mathrm{dL}$ and those with LDLC $\geq 100 \mathrm{mg} / \mathrm{dL}$, elevated plasma sdLDLC levels (the highest quartile) posed a 1.6- and 1.9-fold increased risk of incident CHD, respectively, in a multivariable model compared to the lowest quartile of sdLDLC.

In a cross-sectional study, the Framingham Offspring Study showed that, at the baseline, men had a higher mean sdLDLC levels $(32 \mathrm{mg} / \mathrm{dL})$ than women $(26 \mathrm{mg} / \mathrm{dL})$, and the postmenopausal women had higher sdLDLC values than the premenopausal women ${ }^{11)}$. Moriyama et al. reported that the area under the curve values were 0.771 for LDLC and 0.871 for non-HDLC, revealing a significantly higher predictive value of the more than fourth-quartile sdLDLC value ( $\geq 46 \mathrm{mg} / \mathrm{dL}$ ). This cutoff value is similar to the fourth-quartile sdLDLC values of the Hisayama Study $(44 \mathrm{mg} / \mathrm{dL})$ and the Suita Study (49 $\mathrm{mg} / \mathrm{dL}$ ), which were associated with the development of CHD.

Maeda et al. showed that sdLDLC was positively correlated with both high sensitivity C-reactive protein (hsCRP) and the maximum common carotid artery intima-medial thickness in 481 Japanese-Americans without lipid-lowering medication ${ }^{12)}$. The average sdLDLC values in their subjects with impaired glucose tolerance $(43.7 \mathrm{mg} / \mathrm{dL})$ and those with diabetes mellitus $(47.5 \mathrm{mg} / \mathrm{dL})$ were higher than the average sdLDLC value of the subjects with normal blood sugar $(33.7 \mathrm{mg} / \mathrm{dL})$. Hsu et al. demonstrated positive associations between the sdLDLC level and atherosclerotic risk markers such as fibrinogen, hsCRP, and subclinical diabetes status (impaired fasting glucose and impaired glucose tolerance) in middle-aged Taiwanese without a history of CVD or diabetes mellitus ${ }^{13)}$.

LDL consists of several subclasses of particles with different sizes and densities: large buoyant (lb), intermediate, and small-dense (sd) LDLs. In an LDL fraction analysis, sdLDL (particle size, 15.0-20.0 nm) is separated from lbLDL with the use of a detergent and sphingomyelinase treatment. This method separates the sdLDL fraction with a density from 1.044 to $1.063 \mathrm{~g} / \mathrm{ml}$ using standard clinical laboratory equipment ${ }^{14)}$. sdLDL has a potentially high sensitivity for atherogenic modification compared to the other LDL subfractions, and circulating sdLDL readily undergoes multiple atherogenic modifications in blood plasma (e.g., desialylation, glycation, and oxidation) that further increase its atherogenicity ${ }^{15)}$.

In summary, the Hisayama Study of a Japanese population revealed that the serum sdLDLC level (1) is a relevant residual biomarker for the future development of CHD, (2) offers benefits beyond the serum LDLC level, and (3) is a possible therapeutic target to reduce the burden of CHD. A cohort study with larger sample sizes is awaited, and reproducibility and cutoff values are expected.

\section{Acknowledgments}

This study was supported in part by Grants-inAid for the Japan Agency for Medical Research and Development (JP19dk0207025).

\section{Conflicts of Interests}

All authors have no conflicts of interest.

\section{References}

1) Andersson C, Johnson AD, Benjamin EJ, Levy D, Vasan RS. 70-year legacy of the Framingham Heart Study. Nat Rev Cardiol, 2019; 16: 687-698

2) Wilson PW, D’Agostino RB, Levy D, Belanger AM, Silbershatz H, Kannel WB. Prediction of coronary heart disease using risk factor categories. Circulation, 1998; 97: 1837-1847

3) Pencina MJ, D’Agostino RB, Sr., Larson MG, Massaro JM, Vasan RS. Predicting the 30-year risk of cardiovascular disease: The Framingham Heart Study. Circulation, 2009; 119: 3078-3084

4) Nishimura K, Okamura T, Watanabe M, Nakai M, Takegami M, Higashiyama A, Kokubo Y, Okayama A, Miyamoto Y. Predicting coronary heart disease using risk factor categories for a Japanese urban population, and comparison with the Framingham Risk Score: The Suita Study. J Atheroscler Thromb, 2014; 21: 784-798

5) Kinoshita M, Yokote K, Arai H, Iida M, Ishigaki Y, Ishibashi S, Umemoto S, Egusa G, Ohmura H, Okamura T, 
Kihara S, Koba S, Saito I, Shoji T, Daida H, Tsukamoto K, Deguchi J, Dohi S, Dobashi K, Hamaguchi H, Hara M, Hiro T, Biro S, Fujioka Y, Maruyama C, Miyamoto Y, Murakami Y, Yokode M, Yoshida H, Rakugi H, Wakatsuki A, Yamashita S, Committee for E, Clinical Management of A. Japan Atherosclerosis Society (JAS) Guidelines for Prevention of Atherosclerotic Cardiovascular Diseases 2017. J Atheroscler Thromb, 2018; 25: 846-984

6) Higashioka M, Sakata S, Honda T, Hata J, Yoshida D, Hirakawa Y, Shibata M, Goto K, Kitazono T, Osawa H, Ninomiya T. Small dense low-density lipoprotein-1 cholesterol and the risk of coronary heart disease in a Japanese community. J Atheroscler Thromb, 2020; 27: 669682

7) Hirano T, Ito Y, Saegusa H, Yoshino G. A novel and simple method for quantification of small, dense LDL. J Lipid Res, 2003; 44: 2193-2201

8) Arai H, Kokubo Y, Watanabe M, Sawamura T, Ito Y, Minagawa A, Okamura T, Miyamato Y. Small dense lowdensity lipoproteins cholesterol can predict incident cardiovascular disease in an urban Japanese cohort: The Suita Study. J Atheroscler Thromb, 2013; 20: 195-203

9) Tsai MY, Steffen BT, Guan W, McClelland RL, Warnick R, McConnell J, Hoefner DM, Remaley AT. New automated assay of small dense low-density lipoprotein cholesterol identifies risk of coronary heart disease: The Multiethnic Study of Atherosclerosis. Arterioscler Thromb Vasc Biol, 2014; 34: 196-201

10) Hoogeveen RC, Gaubatz JW, Sun W, Dodge RC, Crosby
JR, Jiang J, Couper D, Virani SS, Kathiresan S, Boerwinkle E, Ballantyne CM. Small dense low-density lipoprotein-cholesterol concentrations predict risk for coronary heart disease: The Atherosclerosis Risk In Communities (ARIC) Study. Arterioscler Thromb Vasc Biol, 2014; 34: 1069-1077

11) Ai M, Otokozawa S, Asztalos BF, Ito Y, Nakajima K, White CC, Cupples LA, Wilson PW, Schaefer EJ. Small dense LDL cholesterol and coronary heart disease: Results from the Framingham Offspring Study. Clin Chem, 2010; 56: 967-976

12) Maeda S, Nakanishi S, Yoneda M, Awaya T, Yamane K, Hirano T, Kohno N. Associations between small dense LDL, HDL subfractions (HDL2, HDL3) and risk of atherosclerosis in Japanese-Americans. J Atheroscler Thromb, 2012; 19: 444-452

13) Hsu SH, Jang MH, Torng PL, Su TC. Positive Association Between Small Dense Low-Density Lipoprotein Cholesterol Concentration and Biomarkers of Inflammation, Thrombosis, and Prediabetes in Non-Diabetic Adults. J Atheroscler Thromb, 2019; 26: 624-635

14) Ivanova EA, Myasoedova VA, Melnichenko AA, Grechko AV, Orekhov AN. Small dense low-density lipoprotein as biomarker for atherosclerotic diseases. Oxid Med Cell Longev, 2017; 2017: 1273042

15) Steinberg D, Parthasarathy S, Carew TE, Khoo JC, Witztum JL. Beyond cholesterol. Modifications of low-density lipoprotein that increase its atherogenicity. N Engl J Med, 1989; 320: 915-924 